\title{
Analysis of welded joint of band-saw blade - influence of annealing process on joint micro- structure and mechanical properties
}

Daniela Kalincová

Faculty of Environmental and Manufacturing technology, Technical University in Zvolen, daniela.kalincova@tuzvo.sk

The paper is aimed at the analysis of a welded band-saw blade joint. The analysis is focused on the influence of joint annealing on the microstructure and mechanical properties. The results of experimental work are focused on an assessment of a set of band-saw blades samples made of material DIN C75. The samples have been welded and evaluated in the states prior and after welding and annealing. The purpose of the experiment was to analyse the influence of different annealing temperatures on structural and mechanical properties and based on the analysis to propose optimal heating temperature that guarantees reliable operation of the band-saw blades. The results of hardness measurement and microstructure evaluation confirmed the need of annealing after welding of band-saw blades.

Keywords: band-saw blades, welding, annealing process, microstructure evaluation, hardness measurement

\section{References}

[1] BUMBÁLEK, B., BUMBÁLEK L. Hard to Machining and Its Better Identification. Manufacturing technology VI., December 2006, p.40-45 ISSN 1213248-9.

[2] HRIVŇÁK, I. Teória zvaritelnosti kovov a zliatin. Bratislava:Veda, 1989. s. 178 - 187. ISBN 80-224-0016-5

[3] CHOTEBORSKY R., NAVRATILOVA M. Experimentalni posouzeni vlivu navarovacich parametru na promisení navarove housenky. Strojirenska technologie, roč. XVI., únor 2011, č. 1, s.44-49 ISSN 201110.

[4] KALINCOVÁ, D (2010): Pílové pásy - analýza vplyvu zvárania na kvalitu ich materiálových vlastností, Vedecká monografia, Technická univerzita vo Zvolene, 66 s. ISBN 978-80-228-2195-7.

[5] KOTUS, M. Aplikácia pulzných zváracích zdrojov pri renovácií súčiastok polnohospodárskych strojov. Dizertačná práca. Nitra : SPU, 2007. $201 \mathrm{s.}$

[6] KOTUS, M. - ČIČO, P. Vplyv parametrov MIG/MAG navárania na tvorbu návaru. Nitra : SPU, 2011. $117 \mathrm{~s}$. ISBN 978-80-552-0553-3.

[7] PILOUS, V., VÁCLAV, J. Nové metalurgické postupy svařováni ocelí. Praha: SNTL, 1985. 328 s. ISBN 04$219-85$.

[8] http://www.bohler.cz, [on-line] [cit. 18.08.2012].

[9] STN EN 1043-1: 1998, Deštruktívne skúšky zvarov kovových materiálov, Skúšanie tvrdosti - Čast’ 1: Skúška tvrdosti spojov zhotovených oblúkovým zváranim.

[10] (www.esabna.com/msds/9002.pdf), [on-line] [cit. 18.08.2012].

[11] KUSMIERCZAK, S. (2011). Corrosion resistence of Titanium alloy. In Proceeding of Engineering for Rural Development. 10th International Conference Engineering for Rural Development. Jelgava. pp. 486-489. ISSN 16913043.

[12] NOVAK, M. (2012). Surfaces with high precision of roughness after grinding. In Manufacturing Technology, vol. 12., no. 12., UJEP, Usti nad Labem, 66-70 pp.

[13] NAPRSTKOVA, N. (2011). Making of experiment for Student usage. In Proceeding of Engineering for Rural Development. 10th International Conference Engineering for Rural Development. Jelgava. pp. 558-563. ISSN 16913043. 